\title{
Evaluation of Surgical Excision of Basal Cell Carcinoma by General Practitioners with Special Interest (GPwSI) within Community Dermatology Clinics
}

\author{
Mohammed Al Abadie ${ }^{* 1,2}$, Shahid Rafiq ${ }^{1-3}$, Shabana Ashad ${ }^{3}$ and Dina Al Abadie ${ }^{4}$ \\ ${ }^{1}$ The Royal Wolverhampton NHS Trust, UK \\ ${ }^{2}$ HealthHarmonie Ltd, Birmingham Uk \\ ${ }^{3}$ Prestbury Medical Practice, Wolverhampton UK \\ ${ }^{4}$ Department of Health Promotion and Public Health, University of West London, UK
}

*Corresponding author: Mohammed Al Abadie, The Royal Wolverhampton NHS Trust, Wolverhampton, UK

\section{ARTICLE INFO}

Received: 幽 July 26, 2019

Published: 慧 August 05, 2019

Citation: Mohammed Al Abadie, Shahid Rafiq, Shabana Ashad, Dina Al Abadie. Evaluation of Surgical Excision of Basal Cell Carcinoma by General Practitioners with Special Interest (GPwSI) within Community Dermatology Clinics. Biomed J Sci \& Tech Res 20(2)-2019. BJSTR. MS.ID.003432.

Keywords: Basal Cell Carcinoma; Community Dermatology; HealthHarmonie

Abbreviations: GPwSI: General Practitioners with Specialist Interest; GPwER: General Practitioners with Extended Roles; CCGs: Clinical Commissioning Groups
ABSTRACT

Background: The demand on secondary care consultations in Dermatology have increased significantly over the years. Dermatology accounts for $21 \%$ of Primary Care Consultations. The regulations in the UK were changed to allow private companies like Health Harmonie to contract the primary care to provide a new tier service i.e. Specialist Community Dermatology Clinics which is consultant led with a mix of professional skills including GPwSI, Dermatosurgeons and CNS nurses.

Aim: To evaluate the performance and competency of GPwSI doctors conducting skin surgery to remove basal cell carcinoma (type of skin cancer), mentored and supervised by a senior Consultant Dermatologist.

Result: Out of 41 suspected basal cell carcinomas excised, 30 were histologically confirmed (73\%).24 patients had complete excision (80\%) while 6 patients $(20 \%)$ were incompletely excised or within a $2 \mathrm{~mm}$ margin. This was due to site limitation, only one patient needed re-excision after MDT discussion. Infection rate of wound was $2.5 \%$.

Conclusion: Community Dermatology Service like the one provided by Health Harmonie can make a significant difference in providing Dermatology Service up to the standard, close to home, within 4 weeks of referral $(100 \%)$ led by a Consultant Dermatologist with primary care doctors and nurses who have special interest in the Specialty.

\section{Introduction}

The Department of Health UK has been developing and maintaining Quality Standards in all Specialties including Dermatology. This has been attracting focus in trying to maintain and improve the quality of service where patients seen in the primary care setting closer to home within reasonable short waiting times. This has led to reducing the demand and pressure on secondary care and allows them to concentrate on advanced/ complex Dermatology patients. The regulations have been changed to allow private companies with a consultant led service to contract directly with the CCG'S (primary care).A new tier of service has been created ie. Specialist Community Dermatology Service when a skill mixes of doctors e.g consultants and GPWSI, CNS nurses can deliver part of the service traditionally sent to the secondary care where patients may wait for 4-6 months for an appointment. Community Dermatology provides a wide range of Dermatology Services including rash and skin lesion diagnosis and management. Specialist clinics can be set up in the community like ultraviolet light therapy, acne and others. Dermatology represents an important 
part of health care provision and makes up a large proportion of a General Practitioners daily workload.

The centre for evidence based Dermatology, Nottingham, found that dermatological conditions formed the most common reason for new GP presentations, with 24\% of the population of England and Wales (12.9 million people) visiting their GP with a skin problem in 2006 [1] with an increase in 5.6\% of new dermatology referrals in England and Wales between 200 and 2007 [2]. Reasons for referral included establishing a diagnosis, treatment or operation (not available in primary care), advice on management and for specialised investigations [3]. The presence of a Basal cell Carcinoma (BCC) is another common reason for a non-urgent dermatology referral. Epidemiological studies by Apalla et al. [4], found that the prevalence of BCC in Europe was 1.4\%, and over the last 40 years increased by $20-80 \%$. This increase in prevalence is thought to be related to poor sun protection, tan-seeking behaviour (sunbathing and indoor tanning) as well as clothing style and ozone depletion [5]. Another fundamental reason for the increase in incidence of BCC and other non-melanoma skin cancers is the prolonged life expectancy in western countries. Data from the Population Division of the Department of Economic and Social Affairs of the United Nations estimated by $2050,32 \%$ of the world population will be above the age of 60 , and as BCC has a predilection for the elderly it is reasonable to assume the incidence of BCC will also increase [6].

As the demand and expectations grow, there is also a need to grow the Dermatology services currently provided within the community and primary care. The Royal College of General Practitioners has sought to do this with the introduction of General Practitioners with Specialist interest (GPwSI) or General Practitioners with extended roles (GPwER). These General Practitioners provide additional specialist dermatological services within the community alongside Dermatology consultants and CNS nurses, which has led to reducing demand and pressure on secondary care and allows them to concentrate on advanced/ complex Dermatology patients [7]. Health Harmonie Limited as private healthcare Provider Company was established in 2003. It has become one of the largest providers of community services in England. To meet the Specialist core demand Health Harmonie developed a model of care that recognizes the importance of drawing upon these skills they developed an effective and efficient service that ensures patients are seen in the right place, by the right clinician the first time in one of these areas. Also, Health Harmonie concentrates on developing the skills of GPs within the specialty both in medical and surgical dermatology.

\section{Aim of the Study}

To evaluate the performance and competency of trained General Practitioners with Special Interest in Dermatology working as part of a team led by Consultant Dermatologist. Areas of evaluation in:

a) Diagnosing and caring basal cell carcinoma skin cancer operation in a community setting. b) Diagnostic accuracy of skin lesions based on clinical and histological evidence.

c) Rate of infection and complete excision and margin of excision were also evaluated.

\section{Method}

A surgical log spreadsheet was created, and a log diary of all surgical procedures was kept from April 2017 to April 2018. Data collection included details to provide context and define case-mix. Data included pre-surgery diagnosis, site of procedure, type of procedure, histological diagnosis, deep and lateral margins if cancer diagnosis. Pre-operative clinical and post-operative histological diagnoses were compared for percentage agreement. For those lesions where the pre- and post-operative diagnoses disagreed, the histological diagnosis was taken as definitive. Exclusion criteria: patients who underwent Diagnostic biopsy for rashes.

\section{Result}

Forty one patients suspected to have BCC's were evaluated of those excised only 30 were histologically confirmed to as BCC (Figure 1), the other lesions included Squamous Cell Carcinoma, Bowen Disease, Hemangioma, Naevus, Lichenoid Keratosis, Dermatofibroma, Dysplastic Actinic Keratosis and a ruptured cyst (Table 1), Giving a diagnostic accuracy of 73\%.As for the margin of clearance the MDT standard of $>1-2 \mathrm{~mm}$ was used for the evaluation.24 basal cell carcinoma lesions (80\%) were completely excised, while $6(20 \%)$ were incompletely excised (Figure 2), significantly due to the limitations of the site of lesion, mainly face. After discussing these 6 patients (20\%) in our local MDT meeting, only one needed re-excision. All procedures were carried out at CQC approved sites with the standard aseptic techniques and standard checks were followed. Out of the 41 patients suspected with basal cell carcinoma, one reported possible infection within 2 weeks after the procedure (2.5\%) (Figure 3).This was a ruptured cyst rather than a basal cell carcinoma. None of the 30 basal cell carcinoma patients reported any infection (Figures 1-3) (Table 1).

Table 1: Histological Diagnosis of lesions clinically suspicious of basal cell carcinoma.

\begin{tabular}{|c|c|c|}
\hline \multicolumn{2}{|c|}{ Basal Cell Carcinoma } & Total \\
\hline \multirow{3}{*}{} & Squamous Cell Carcinoma & $\mathbf{3 0}$ \\
\cline { 2 - 3 } & Bowen Disease & 1 \\
\cline { 2 - 3 } & Haemangioma & 1 \\
\cline { 2 - 3 } & Naevus & 1 \\
\cline { 2 - 3 } & Lichenoid Keratosis & 1 \\
\cline { 2 - 3 } & Dermatofibroma & 3 \\
\cline { 2 - 3 } & Dysplastic Actinic Keratosis & 1 \\
\cline { 2 - 3 } & Ruptured Cyst & 1 \\
\cline { 2 - 3 } & & 2 \\
\cline { 2 - 3 } & Her & 1 \\
\hline
\end{tabular}




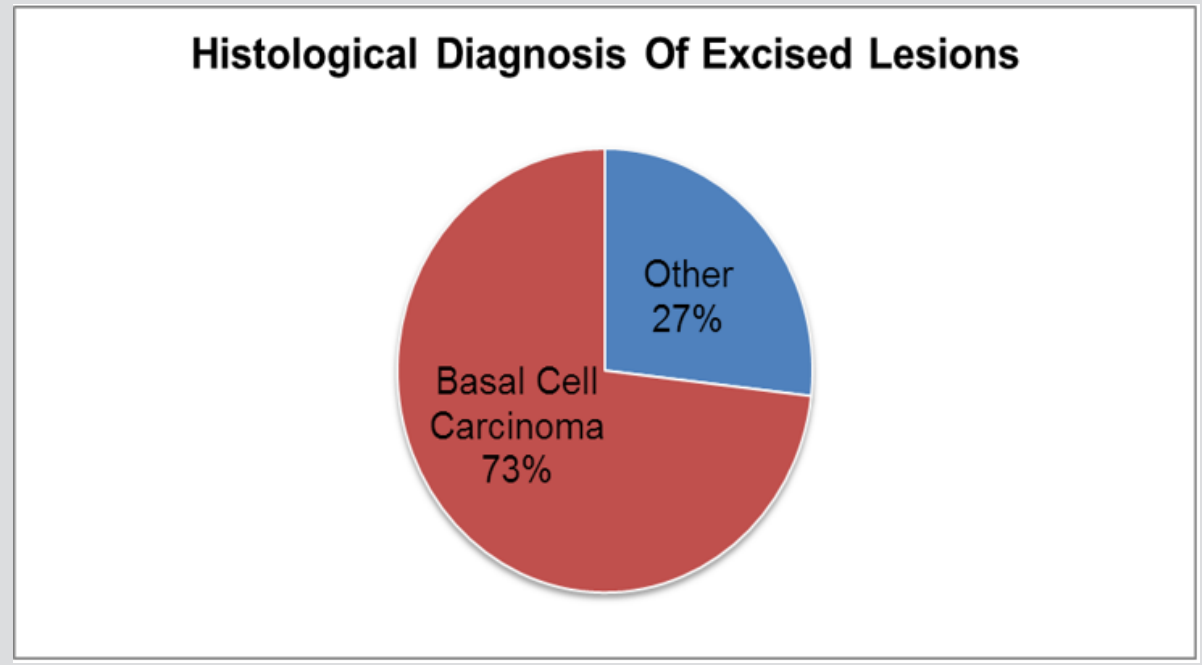

Figure 1: Histological diagnosis of excised lesions clinically suspicious of Basal Cell Carcinoma. Diagnostic Accuracy of $73 \%$.

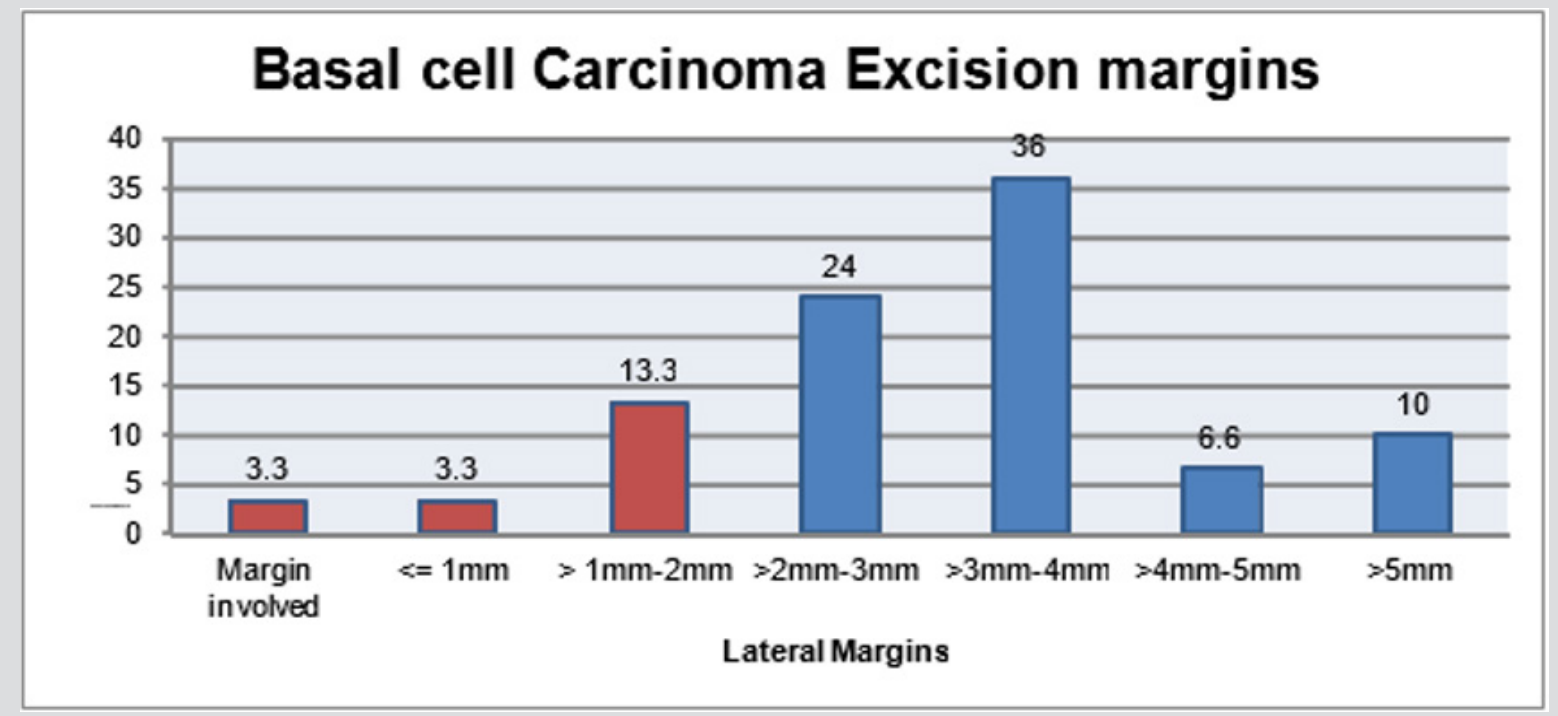

Figure 2: Basal Cell Carcinoma excision margins, $80 \%$ completely excised (margins $>2 \mathrm{~mm}$ ).

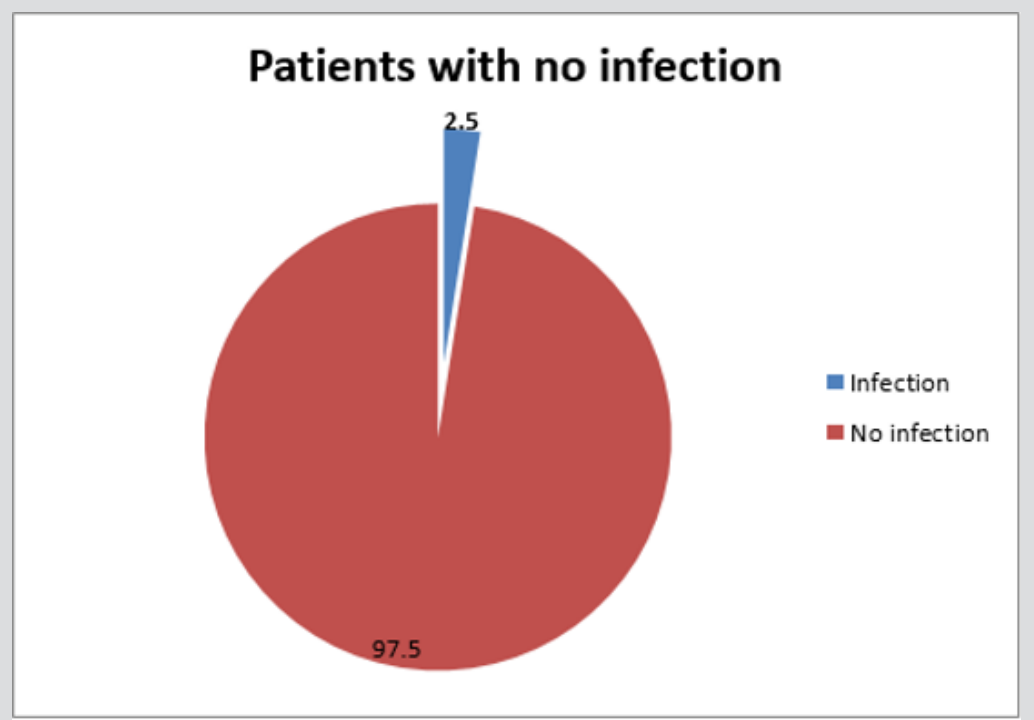

Figure 3: Infection rate among the 41 procedures. 


\section{Discussion}

This retrospective analysis of the surgical logbook of a General Practitioner with a specialist interest in Dermatology revealed between April 2017 and April 2018 there were 414 procedures undertaken of which $10 \%$ (41) were excisions for suspected Basal Cell Carcinomas. There was a histologically proven diagnostic accuracy of 73\%, and 5\% [2] of the lesions that did not concord with the histological diagnosis proved to be Squamous Cell Carcinomas. Although there is limited amount of data available to compare diagnostic accuracy research conducted by Heal et al. [8] in Australia found that clinical diagnosis for BCC was $69.3 \%$ sensitive, lower than that shown in this analysis. $20 \%$ of the lesions excised did not have clear margins and 2-5 year follow up showed a reoccurrence rate of between $30-41 \%$, with reoccurrence BCC being harder to cure then the primary disease [9]. Although Dermatology accounts for 21\% of Primary Care Consultations [10], GP registrar training in this area is not a compulsory, and therefore leaves newly qualified General Practitioners ill-equipped to deal with what forms a major part of their workload [3].

Continued training and learning in this area is essential to build confidence and diagnostic accuracy. The NHS Plan 2000 [11] sought to promote the concept of General Practitioners with specialist interests, in order to increase service capacity in the face of rising demand, to reduce excessive waiting lists for outpatient appointments and to improve accessibility and convenience of care [12]. As with any new service Quality standards need to be maintained, and regular appraisal and revalidation schemes as set up but the Royal College of General Practitioners ensures that this happens [13]. Health Harmonie model of care for Dermatology patients seen in the community led to create a complementary service to support the secondary care, at the same time work closely with General Practitioners to provide more of the specialist care closer to home with patients seen within a short time. Health Harmonie is a Community Healthcare Provider founded in $2003.100 \%$ of the work is commissioned by the NHS.

Currently it undertakes Community Services for 42 Clinical Commissioning Groups (CCGs) across the UK. Specialties include Community Dermatology including 2WW NHS Trust Support. During the year $17 / 18,120,000$ patient appointments were undertaken, achieving $98.2 \%$ in patients stating that they would

\section{ISSN: 2574-1241}

DOI: 10.26717/BJSTR.2019.20.003432

Mohammed Al Abadie. Biomed J Sci \& Tech Res

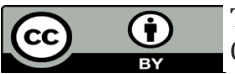

This work is licensed under Creative Commons Attribution 4.0 License

Submission Link: https://biomedres.us/submit-manuscript.php recommend our service to family or friends. $100 \%$ of patients were offered appointments within 28 days of receipt of referral.92.4\% were seen within 28 days of receipt of referral. $100 \%$ of patients offered routine appointment within 28 days of receipt of referral, $92.4 \%$ of our patients have been seen within 28 days of receipt of referral, $76.5 \%$ of patients were seen within 14 days of receipt of referral and $100 \%$ of Consultation reports were issued electronically to GPs within 48 hours of the appointment.

\section{Acknowledgement}

None.

\section{Conflict of Interest}

No conflict of interest.

\section{References}

1. Schofield J, Grindlay D, Williams H (2009) Skin conditions in the UK: a health care needs assessment. Nottingham: Centre of Evidence Based Dermatology, University of Nottingham.

2. (2013) British Association of Dermatologists, Lessons for the NHS: commissioning a dermatology service. Based on case studies from England.

3. (2019) The Kings Fund, The quality of GP diagnosis and referral. GP enquiry paper.

4. Apalla Z, Lallas A, Sotiriou E, Lazaridou E, Ioannides D, et al. (2017) Epidemiological trends in skin cancer. Dermatol PractConcept 7(2): 1-6.

5. Leiter U, Eigentler T, Garbe C (2014) Epidemiology of skin cancer. Adv Exp Med Biol 810: 120-140.

6. (2013) United Nations, Department of Economic and Social Affairs, Population Division, World Population Ageing 2013. ST/ ESA/ SER.A/348.

7. Salisbury C, Noble A, Horrocks S, Crosby Z, Harrison V, et al. (2005) Evaluation of a general practitioner with special interest service for dermatology: randomised controlled trial. BMJ.

8. Heal CF, Raasch BA, Buettner PG, Weedon D (2008) Accuracy of clinical diagnosis of skin lesions.Br J Dermatol 159(3): 661-668.

9. Telfer NR, Colver GB, Morton CA (2008) Guidelines for the management of basal cell carcinoma. BJ Dermatol 159(1): 35-48.

10. Julian CG (1999) Dermatology in general practice. Br J Dermatol 141(3): 518-520.

11. (2000) Department of health. The NHS Plan. A plan for investment. A plan for reform, DoH, London, UK.

12. (2003) Department of Health. Practitioners with special interests: bringing services closer to patients. DoH, London, UK.

13. (2018) Guidance and competences to support the accreditation of GPs with Extended Roles (GPwERs).

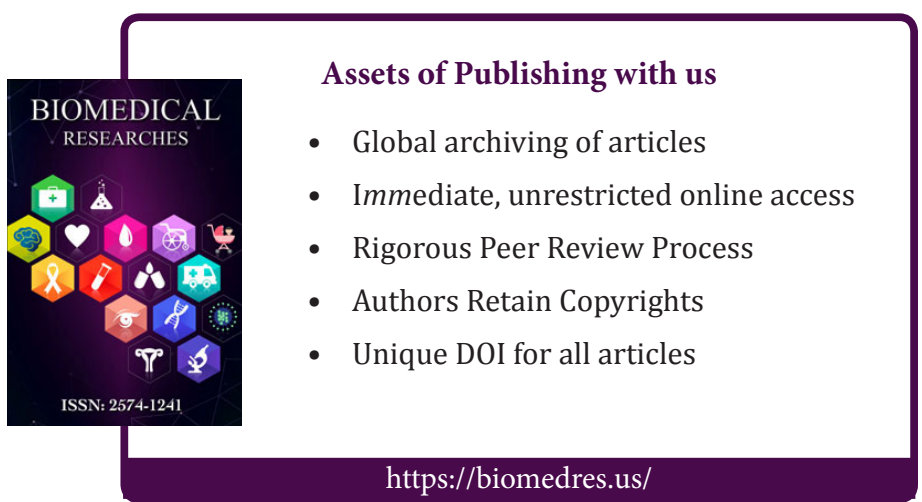

